\title{
Reflexões acerca da Implantação e Funcionamento de um Plantão de Emergência em Saúde Mental
}

Reflections about the implant and the operation of a mental health emergency attendance

Ivarlete Guimarães de França

Universidade Federal do Rio Grande do Sul

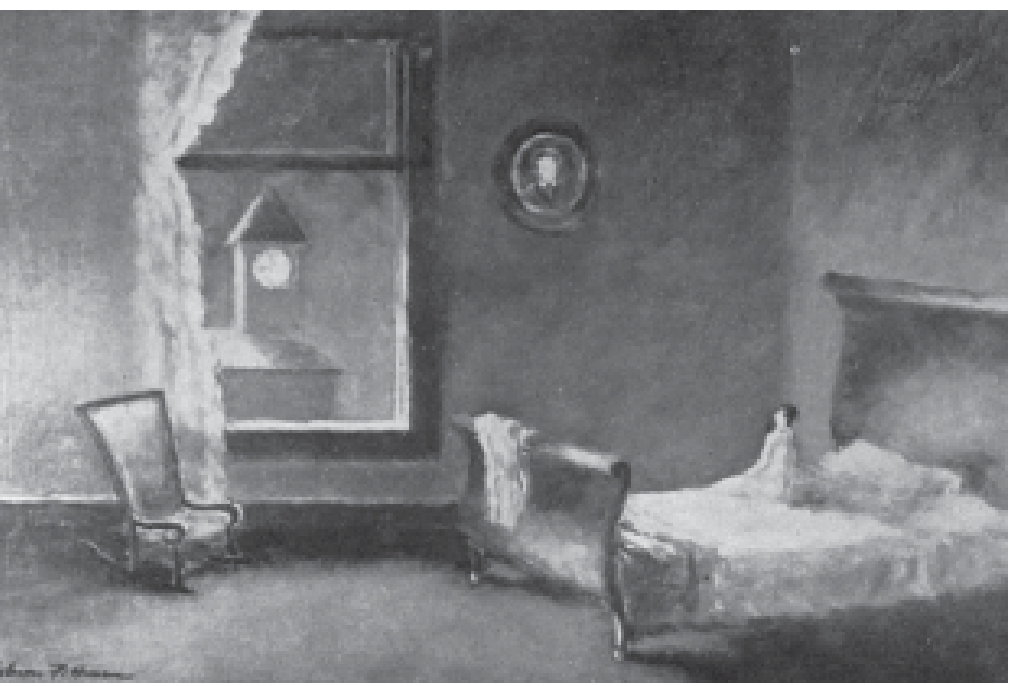


Resumo: Este relato propõe uma reflexão sobre os desafios enfrentados pela equipe de saúde mental frente à criação de um serviço de emergência em saúde mental fora do hospital psiquiátrico. Enfatiza o acolhimento como uma estratégia clínica de atenção ao sofrimento psíquico para a superação de barreiras encontradas pelos indivíduos e grupos em situação de risco, desvantagem social e sofrimento mental. O desafio pretendido remonta à possibilidade de substituir um modelo hospitalar de atendimento pela inclusão em uma rede de cuidados em saúde, comunitária e ambulatorial.

Palavras-chave: acolhimento, emergência, saúde mental.

Abstract: This paper proposes a reflection on the challenges faced by a mental health staff to create a mental health emergency service outside the context of a psychiatric hospital. It emphasizes embracement as a clinic strategy to respond to psychic suffering and to overcome the hardship found by individuals and groups in at-risk situations, social disadvantages and mental suffering. The challenge proposed lies on the possibility to substitute an inpatient health model for a community and outpatient health care network.

Key words: embracement, emergency, mental health.

Este artigo registra uma experiência realizada em Porto Alegre, de janeiro a dezembro de 1999, durante o primeiro ano de funcionamento do Plantão de Emergência em Saúde Mental (PESM). Procura refletir sobre a importância do acolhimento oferecido aos usuários do serviço de emergência como forma de criar novas possibilidades de intervenção que possam transformar olhares e atitudes que a cidade desenvolve quanto aos portadores de sofrimento mental.

A importância dessa vivência remonta ao desafio de transformar um serviço de emergência em saúde mental fora do hospital psiquiátrico em um lugar diferenciado das emergências tradicionais, tendo o pronto acolhimento como a principal ferramenta e tecnologia utilizada para transpor as diversas barreiras que costumam impedir o acesso e a inserção dos indivíduos e dos grupos em situação de risco, desvantagem, vulnerabilidade social e sofrimento mental.

A tarefa colocada ao serviço debruça-se, também, sobre o desafio do serviço em diminuir as internações hospitalares e oferecer uma atenção singularizada a cada situação de emergência psíquica que ocorria na cidade, colocando em prática as Diretrizes de uma Política de Saúde Mental da Secretaria Municipal de Saúde, em vigência naquele momento, preconizada na $2^{a}$ Conferência Nacional de Saúde Mental, de 1992.

A partir de um levantamento de dados quantitativos a respeito do número de internações psiquiátricas encaminhadas semestralmente pelo Plantão, pretendia-se medir o impacto do mesmo sobre essas hospitalizações e conhecer as principais
O desafio pretendido remonta à possibilidade de substituir um modelo hospitalar de atendimento pela inclusão em uma rede de cuidados em saúde, comunitária e ambulatorial.
1 Em psicodrama, as sessões são conduzidas por uma equipe psicoterapêtica denominada "unidade funcional", que é composta por um "diretor" e um "egoauxiliar". 
causas da procura por atendimento de emergência em saúde mental na cidade de Porto Alegre.

Objetivava-se, também, com a obtenção desses dados, futuramente, regular as internações hospitalares na área de saúde mental, incluindo-as no sistema da Central de Regulação de Leitos já existente na Rede Municipal de Saúde e propor aos demais serviços de saúde a implantação de um programa de acolhimento extensivo a toda a rede de atendimento.

\section{A integralidade na atenção para superação da prática manicomial e implantação de um modelo substitutivo extra- hospitalar}

A prática e as ações de trabalho realizadas pelo Plantão de Emergência em Saúde Mental (PESM) no período de 1999 até o início de 2001, período a que se refere este relato, eram norteadas por um modelo de atenção à saúde baseado no princípio da integralidade, mantendo o foco da intervenção no indivíduo e na sua condição de vida social. Com essa forma de intervir, buscava-se promover o vínculo dos usuários a um tratamento ambulatorial, e, com isso, evitar seu desligamento da comunidade, introduzindo um modelo extra-hospitalar de atenção que pudesse romper gradativamente com a prática hospitalocêntrica, cuja tarefa entendíamos ser de responsabilidade de todas as instituições de saúde mental, substitutivas e comprometidas com a reforma psiquiátrica.

Segundo as diretrizes do Guia dos Serviços de Saúde Mental do Estado do Rio Grande do Sul (2002), a substituição da prática hospitalar é perseguida por meio da promoção da eqüidade, através da oferta de acolhimento incondicional a cada sujeito que chega em sofrimento mental, buscando atender as diferentes necessidades apresentadas, procurando contemplar as diversas etapas do desenvolvimento (crianças, adolescentes e adultos) e estabelecer um fluxo com os demais serviços (sanitários, assistenciais, educativos e de reabilitação).

Propõe, ainda, o Guia (op. cit.), a efetivação de parcerias com outras iniciativas junto à sociedade civil organizada, utilizando os recursos comunitários para obter maior resolubilidade em suas ações e ampliar a capacidade de atendimento, evitando, assim, recorrer a internações hospitalares. Entretanto, é importante ressaltar que essa prática pode colocar em xeque a estrutura sanitária e social toda vez que for constatada uma certa incapacidade de respostas às exigências em saúde mental, principalmente quando se tratar de acolher indivíduos em situações de rua, de abandono familiar e de sofrimento mental. Superar tal barreira social e garantir acesso a todos os excluídos torna-se, portanto, não só um exercício terapêutico desafiador mas também o grande salto de qualidade a ser perseguido no âmbito das políticas públicas de saúde.

Cabe observar que essa lógica de serviço substitutivo ao modelo hospitalar, através da implantação de uma rede de atenção integral em saúde mental, teve suas raízes nas lutas dos movimentos de saúde mental que, negando o manicômio, apontaram outras alternativas possíveis de atenção e 
que, portanto, embora não tenham uma visão legalista ou reformista, seus cuidados e atendimentos procuram garantir todos os direitos dos usuários determinados em suas legislações (Lei da Reforma Psiquiátrica, no 9716/92, Lei Federal no 10.216/01 e a Lei Orgânica da Saúde, no 8.080/90).

Mesmo assim, só é possível constatar a materialização dessas idéias na medida em que os serviços de saúde promovam a ampliação da autonomia das pessoas, comunidades e equipes de operadores e sejam centrados nos princípios de cidadania, participação, descentralização e intersetorialidade, permitindo aos usuários a manutenção e o resgate dos vínculos sociais que acabam se perdendo diante de longas e repetidas internações psiquiátricas (Ministério da Saúde, 1990).

Essa concepção de trabalho exige uma mudança no conjunto das ações executadas na saúde, que devem ocorrer de forma integrada para que cada sujeito que chegue em crise ao serviço de saúde mental possa ser acolhido e avaliado pelos profissionais da equipe e, conforme a necessidade, permanecer em atendimento médico, de enfermagem, psicológico e social até estar em condições de retornar a suas comunidades, podendo continuar o tratamento mais próximo de seu domicílio, conforme a evolução do quadro apresentado.

Entretanto, para determinar uma estratégia de intervenção individualizada em cada situação apresentada, a avaliação deve procurar investigar não somente o diagnóstico da patologia mas analisar também aquelas variáveis que se encontram na "sombra", conforme refere Saraceno (1997), que são: os recursos do paciente e de seu contexto bem como os recursos do serviço de atenção e de seu contexto.

Para fazer frente a todos esses objetivos, fezse necessário desenvolver uma linha de atuação tão complexa quanto a proposta colocada. Nesse sentido, evidenciou-se, por parte da equipe do Plantão, a necessidade de aprofundar a concepção teórica sobre saúde mental e investir em uma prática, naquele momento, que foi denominada de clínica do acolhimento.

\section{Perspectivas para uma clínica do acolhimento}

Tomando como referência as orientações da Área Técnica de Saúde Mental da Secretaria de Políticas de Saúde do MS (1999) e o Guia de Serviços de Saúde Mental da SES,RS (2002), verifica-se que as Diretrizes dos Serviços de Saúde se articulam, formando um todo que define o modelo assistencial e assinalam a adoção de uma prática com base na acolhida ou acolhimento, no vínculo e na responsabilidade.

Acolhimento refere-se, então, à capacidade de estar disponível para escutar e dialogar com o outro que procura ajuda, incondicionalmente, oferecendo atendimento imediato (Guia de Serviços de Saúde Mental, 2002).

Pode-se dizer que o acolhimento se contrapõe aos agendamentos tradicionais praticados nos setores de saúde por construir uma simbologia em saúde, cujo objetivo é dar um sentido para a busca do 
sujeito e transformar sua procura infinita num encontro imediato, onde o sintoma possa ser reelaborado como significante de uma realidade que se tornou inteligível num momento transitório de vida. Segundo Pitta (1996), implica convencer as pessoas de que suas vidas, e que elas, em si, valem a pena, e que esses sentimentos devem contagiar a todos nos diferentes momentos em que prevalecerem a repulsa e o distanciamento nas relações.

A mesma autora, referindo-se à desinstitucionalização das instituições de saúde mental, enfatiza que: "(...) temos que desenvolver uma tecnologia de cuidados que considere um compromisso ético de acolher e cuidar de pessoas culturalmente desinseridas, socialmente abominadas, transfigurando-as em sujeitos amorosos, passíveis de alguma inteligibilidade, de provocar simpatia, solidariedade e alianças terapêuticas" (op. cit., pp.154-5).

Essa é uma abordagem que se propõe a romper com a cronificação e a reverter a rigidez institucional, de modo que o adoecer psíquico possa ser entendido como um apelo, uma tentativa de estabelecer relações satisfatórias. Procurando escutar livremente o sofrimento, criando dispositivos de continência para a angústia dos sujeitos, estendendo um olhar aos seus pares, administrando conflitos, oferecendo acolhida para as urgências, evitando o estigma de certos signos psiquiátricos, permitindo a livre expressão do pedido de ajuda e buscando, em primeiro plano, oferecer atenção ao sofrimento e não à eliminação pura e simples do sintoma.
Na concepção de Pitta (1996), escutar esconde uma intencionalidade ética que distingue 'nós dos outros'. Escutar é nada mais que um ato psicológico que busca alcançar algum registro que permita um campo de trocas. "Existe uma terceira escuta que não se contenta com os signos classificados, determinados, e admite um espaço intersubjetivo de interpretação, onde o que se escuta traz necessariamente um apelo do 'escuta-me', num jogo transferencial já não concebível sem a penetração no mundo inconsciente" ( p.156).

O acolhimento pode ser, então, concebido como a mais importante tecnologia de um serviço de emergência, apresentando-se, em última instância, como um território livre para as manifestações do desejo, possibilitando, a partir da reconstituição do sujeito, criar um lugar de referência onde a desorganização e a reorganização podem coexistir em sua relação dialética enquanto possibilidade de reestruturação.

Através da acolhida, demarca-se o lugar da escuta e expressa-se a singularidade, fica estabelecida a relação de confiança e de aceitação. A diferença é reconhecida como um valor que permite resgatar a identidade e o pertencimento; o Eu e o Outro tornamse cúmplices nesse processo vincular em que, na visão de Pichon-Riviére (1991, p. 24), "Cada indivíduo se relaciona com o outro ou outros, criando uma estrutura particular a cada caso e a cada momento que chamamos de vínculo". A posição desse autor é importante na compreensão do vínculo, embora haja ressalvas aos seus posicionamentos, qualificados como higienistas e profiláticos em saúde mental. 
Podemos entender, do ponto de vista da psicanálise, o vínculo como a relação transferencial que, segundo Laplanche e Pontalis (1992, p. 518), é como “(...) o terreno em que se representa, em sua atualidade irrecusável, a problemática singular do paciente, em que se encontra confrontado com sua existência, com a permanência, com a força de seus desejos e fantasias inconscientes".

Agora remetendo-nos à concepção de responsabilidade, é possível compreender que esta se refere ao compromisso ético assumido perante as demandas dos sujeitos, sejam estas individuais ou coletivas, e que somente a partir da reciprocidade desse compromisso é possível estabelecer os contratos de cuidados e garantir que uma participação mais ativa do usuário nesse processo possa resultar na elaboração do plano terapêutico.

A responsabilidade é fundamental, não apenas por parte do serviço de saúde mas também do usuário, para que este possa exercitar sua autonomia, pois será o meio pelo qual ele conquistará as condições materiais necessárias ao estabelecimento do contrato social. Conforme adverte Kinoshita (1996, pp. 56-7), “A contratualidade do usuário primeiramente vai estar determinada pela relação estabelecida pelos próprios profissionais que o atendem. Só estes podem usar de seu poder para aumentar o poder do usuário. Depois, pela capacidade de elaborar projetos que modifiquem as condições concretas de vida, de modo que a subjetividade do usuário possa enriquecerse e para que as abordagens terapêuticas possam contextualizar-se".
De acordo com esse autor, devemos entender a autonomia como a capacidade de o indivíduo criar novas ordens e gerar normas para sua vida conforme as diversas situações que enfrente, não devendo, no entanto, ser confundida com autosuficiência ou independência. "Somos mais autônomos quanto mais dependentes de tantas mais coisas pudermos ser, pois isto ampliará as nossas possibilidades de estabelecer novas normas e novos ordenamentos para a vida" (op. cit., p. 57).

\section{Saúde mental: registros de uma trajetória}

Desde o século XVIII, a Medicina psiquiátrica institui-se como incremento da atividade médica, tendo como objeto a doença mental. Trabalhando com os limites do sofrimento psíquico, a psiquiatria construiu versões de possibilidades, necessidades e julgamentos, elegendo o manicômio como local da loucura, justificando, cientificamente, a exclusão dos insanos do meio social (Foucault, 1993).

Como é possível observar, a loucura, ao longo da História, passa por várias formas de percepção: como ameaça à ordem social, como expressão do desatino, perda da razão, anormalidade e transtorno. $\mathrm{O}$ sujeito louco, por exemplo, chegou a ser considerado por Lombroso (2001), médico italiano, em seu livro publicado em 1876, sob o título "O Homem Delinqüente", como uma variante do criminoso nato. Influenciado por essa lógica de pensamento, a internação dos portadores de sofrimento mental em manicômio prestou-se a funcionar nos mesmos moldes reproduzidos 
pela prisão, dando origem a estigmas e preconceitos que vão sendo permanentemente reeditados no decorrer do tempo. Até a década de 70, por exemplo, perdurava forte prevalência de tal modelo hegemônico, cujo centro do atendimento às doenças mentais era o hospital psiquiátrico, baseando-se a oferta de tratamento na internação.

Para Teixeira (1989), foi com a Reforma Sanitária, nos idos dos anos 80, que se iniciou uma reversão da tendência hospitalocêntrica e um rompimento com a concepção negativa do modelo de saúde, definida como ausência de doença, dando lugar, assim, à concepção afirmativa do conceito de saúde como "resultante das condições materiais de vida da população de uma determinada sociedade", cuja compreensão conceitual se dá através das exigências em investimentos na qualidade de vida e cidadania. A saúde, então, passa a ser entendida como "Direito de todos e dever do Estado", conforme apontou a VIII Conferência Nacional de Saúde (1986).

Impulsionada por essas transformações sociais, políticas e econômicas que influenciavam o cenário brasileiro, em 1987, uma plenária de trabalhadores em saúde mental de todo o País, incluindo o Rio Grande do Sul, desencadeou um processo de mudança na ótica da atenção psiquiátrica. Contando com a presença de usuários e familiares, nessa plenária, instituiu-se o dia 18 de maio como Dia Nacional da Luta Antimanicomial, passando-se, então, a lutar "por uma sociedade sem manicômios", enfatizando aspectos como liberdade, inclusão social e o resgate da cidadania dos portadores de sofrimento psíquico através da conquista dos seus direitos (Amarante, 1996). Essa bandeira foi assumida pelo Fórum Gaúcho de Saúde Mental, que até hoje continua sendo referência para essa luta no Estado do Rio Grande do Sul.

Com as Conferências Nacionais de Saúde Mental ( $1^{\mathrm{a}}$ e $2^{\mathrm{a}}$, respectivamente, em 1987 e 1992), ampliou-se o conceito de cidadania com a participação dos sujeitos em todos os aspectos da vida social, reforçando a necessidade da criação dos serviços substitutivos extra-hospitalares. Todo esse processo foi legitimado pela Constituição Federal de 1988, por meio da qual as ações e os serviços de saúde passaram a integrar uma rede regionalizada, hierarquizada, constituindo-se em um Sistema Único de Saúde de acesso universal.

Ainda no campo da saúde mental, a Declaração de Caracas, de 1990, veio estabelecer a garantia dos direitos humanos e civis dos portadores de sofrimento psíquico, ressaltando a importância da implantação de um modelo de atenção à saúde mental diversificado, comunitário, integral, contínuo e preventivo, incluindo a atenção primária em saúde mental, promovendo a inclusão social e resgatando vínculos através da recuperação e do fortalecimento de laços afetivos e solidários com suas redes sociais (Organização Panamericana da Saúde, 1990).

Outro marco fundamental foi a Lei da Reforma Psiquiátrica do Estado do Rio Grande do Sul, aprovada e sancionada em 07 de agosto de 1992. Tal lei veio determinar a substituição progressiva dos 
hospitais psiquiátricos por uma rede de atenção integral em saúde mental, composta por diversos recursos sanitários e sociais, buscando integrar o portador de sofrimento mental à comunidade.

Em Porto Alegre, como resultado dos processos de Reforma Sanitária e Psiquiátrica, visando a colocar em prática as idéias produzidas durante a $2^{\text {a }}$ Conferência Nacional de Saúde Mental (1992) para a superação do modelo asilar, a Comissão de Saúde Mental elaborou um relatório no ano de 1993. Neste, fornecemse as diretrizes para a organização e a criação dos serviços de saúde mental no município, incluindo as equipes de saúde das unidades básicas, equipes de saúde mental especializadas, centros de atenção integral à saúde mental (CAIS Mental), oficinas terapêuticas e de geração de renda, moradias protegidas (atualmente, serviços residenciais terapêuticos), serviços de emergência em saúde mental (PESM) e abertura de leitos psiquiátricos em hospital geral, articulados em rede, visando a atender aos diferentes níveis de atenção à saúde mental considerando seu grau de complexidade.

Com o processo de municipalização dos serviços de saúde de Porto Alegre, iniciado em 1994 e concluído em 1996 (Diário Oficial de Porto Alegre, 11/01/95), colocouse o desafio específico para o atendimento da população mais próximo de seu local de moradia, acelerando o curso de descentralização da atenção em saúde mental na cidade. Com o fechamento da Central de Psiquiatria, a partir de julho de 1998, foi possível a formação e ampliação das equipes de saúde mental em diversos distritos sanitários e a criação do Plantão de Emergência em Saúde Mental (PESM), com funcionamento diurno (inaugurado em janeiro de 1999), buscando a efetivação da Rede de Atenção Integral em Saúde Mental.

Após um ano de funcionamento, foi ampliado o horário de atendimento do referido plantão de 12 para 24 horas. Essa medida veio atender aos princípios que norteiam a organização dessa rede, garantindo agilidade no acolhimento e no atendimento a situações de emergência, gerando modalidades de intervenção em crises e evitando ao máximo as internações psiquiátricas, além de servir de suporte para os demais serviços da rede sanitária e social da cidade de Porto Alegre.

\section{Alguns pressupostos que embasaram esta proposta}

Segundo a visão psiquiátrica tradicional, emergência psiquiátrica é entendida como um distúrbio de pensamentos, sentimentos ou ações, para o qual é necessário um tratamento imediato, conforme assinalam Kaplan \& Sadock (1990).

Já Flek (1996, p. 34), ao enfocar a teoria do stress, chama a atenção para as freqüentes situações de crise presentes em um serviço de emergência e as conceitua como "(...) resultantes de um conflito entre um fator desencadeante e os recursos do paciente (internos e externos) para lidar com o estressor".

Constata-se, através dessas teorias, que existem inúmeros conceitos sobre 
emergências, referindo-se, também, a todas aquelas situações de crise e de agravo à saúde que causam sofrimento psíquico e que requerem um pronto acolhimento. Por sofrimento psíquico, pode-se entender, ainda, um "Conjunto de mal-estares e dificuldades de conviver com a multiplicidade contraditória de significados oriundos do antagonismo subjetividade e objetividade. Caracteriza-se por dificuldade de operar planos e definir sentido da vida, aliada ao sentimento de impotência e vazio do eu, experimentado como coisa alheia", conforme citação de Sampaio (1999, p. 25).

Por essa multiplicidade de conceitos que expressa uma necessidade premente que se tem em definir emergência, atentamos para a existência de outras formas de conceber os momentos de crise, encarada como nova oportunidade.Assim, sem se preocupar com tais definições, Long (1994) vai mais além e faz importantes reflexões acerca daquilo que ela chama de urgência subjetiva, entendida apenas como a necessidade do paciente de ser escutado.

Diante da provocação colocada pela autora, vê-se que o desafio não está em procurar uma definição que traduza sofrimento psíquico ou emergência, enquadrando ambos em algum conceito hermético, mas, sim, em investir no processo de acolhida, direcionando a investigação, o olhar e a escuta para todos os aspectos possíveis (objetivos e subjetivos) que possam dar continência à imensurável dor mental e venham produzir algum sentido para a vida daquele que chega com pedido de ajuda.
Podemos verificar, então, conforme afirma Saraceno(1997), que a emergência é um conjunto de interesses afetivos e práticos contrastantes, onde o paciente e sua crise são apenas uma parte e não a totalidade , devendo a equipe de saúde mental levar em conta todas essas diferentes possibilidades no momento de avaliar.

Para tanto, faz-se necessário tecer algumas considerações sobre crise.

Atualmente, ainda se convive com diversas concepções acerca das situações de crise e suas diferentes abordagens. No que tange à saúde mental, torna-se ainda mais complexa uma definição.

Segundo Delgado (1991), constata-se uma tendência a utilizar-se, de forma acrítica, de determinados esquemas técnicos de intervenção, de caráter classificatório, que homologam comportamentos e faixas de problemas, para os quais se costuma prever sempre respostas pré-formuladas, buscando interpretar essas condições dentro de parâmetros definidos e controláveis.

Para o autor, tal visão mostra-se reducionista na medida em que simplifica a um sintoma a complexidade da existência de uma pessoa em sofrimento. Em conseqüencia, isso reflete uma visão hospitalocêntrica de "resolução", uma vez que busca suprimir a crise, tolhendo o investimento em novas possibilidades de intervenções terapêuticas.

Do ponto de vista de Delgado (1991), diante de uma crise, devem-se considerar, em primeiro lugar, os fatores de ordem subjetiva e, ao mesmo tempo, procurar manter uma 
posição crítica e atenta às várias circunstâncias que podem fazê-la emergir, sejam elas culturais, sociais, familiares, pessoais, e que, muitas vezes, estão relacionadas a uma burocratizada e cansativa trajetória por serviços de saúde em busca de atendimento, sem obter resposta. Resulta que essa "maratona", além de colocar em xeque a estrutura sanitária existente, faz com que a falta de acolhimento imediato, em "algum lugar" dessa estrutura, transforme um momento de crise emocional, que poderia ser transitório, numa prática de reclusão hospitalar desnecessária que pode deixar seqüelas na vida dos indivíduos.

Deve-se provocar uma reflexão, voltada para o desafio de construir um modelo assistencial mais resolutivo e antimanicomial, sem desconsiderar os procedimentos tradicionalmente preconizados, conforme princípios cientificamente validados. Assim, para Delgado (op. cit.), trata-se de poder pensar as intervenções em crise sob o enfoque de uma multiplicidade de desdobramentos, considerando a singularidade, a história de vida e o lugar que a crise vem ocupar nessa trama de conflitos e mal-estar que envolve o indivíduo, sua família e as relações sociais estabelecidas em determinado momento da vida. Delineia-se, assim, a possibilidade de rever os limites e o alcance das novas práticas públicas de atendimento a situações de sofrimento psíquico.

Com relação às práticas públicas de atendimento à saúde mental, segundo Saraceno (1997), para além das intervenções terapêuticas convencionais, baseadas nos imediatos encaminhamentos dos pacientes para "outros lugares", é importante que os serviços de urgência ofereçam uma "escuta" apurada e uma abordagem eficiente e adequada, com uma avaliação humanizada e singular de uma crise em curso, acionando, para tanto, diversos recursos terapêuticos de intervenção imediata. Tais recursos só podem ser acionados na medida em que exista um trabalho articulado a uma rede de atendimento.

Todas essas proposições fundamentaram a proposta de trabalho implementada pelo Plantão de Emergência em Saúde Mental (PESM), buscando acolher as crises e abrir novas perspectivas de vida mediante um atendimento pontual, porém efetivo, contando com o trabalho da equipe interdisciplinar e com o apoio de leitos para observação à disposição no próprio espaço do Plantão sempre que houvesse necessidade.

Para tanto, nessa experiência, a intervenção de uma equipe interdisciplinar foi imprescindível para assegurar uma abordagem terapêutica integral, capaz de cumprir também o papel de mediadora do serviço com os demais recursos da rede sanitária e social, cabendo à equipe a função de interlocutora junto à clientela, cujas necessidades envolviam família, trabalho, Justiça e outras situações.

Sobre as equipes de trabalho, as orientações do Ministério da Saúde (1990), baseadas na concepção de que a saúde mental é um campo de permanente ajustamento das idéias que determinada sociedade tem sobre si mesma e seus indivíduos, são de que as propostas das equipes dos serviços devem 
ser constantemente relativizadas para garantir a efetivação e a qualidade das mudanças necessárias à desconstrução dos estigmas, de modo que a comunidade possa entender a doença mental como um acontecimento natural dentro do contexto do adoecer.

Propõe, ainda, visto a crescente ampliação dos saberes e a complexa natureza do objeto doença mental, a intervenção da equipe interdisciplinar como instrumento privilegiado de trabalho, pois oferece lugar para que os saberes se ponham à prova, se limitem, se critiquem e se ampliem, produzindo novos conhecimentos e novas práticas de intervenção em crise, conferindo novo significado aos saberes já estabelecidos e proporcionando uma nova produção de sentidos.

Com base nessas premissas, remetemo-nos ao Guia de Serviços de Saúde Mental da Secretaria da Saúde do RS (2002), que apregoa que o trabalho da equipe deverá incluir um permanente repensar de sua prática cotidiana e das relações estabelecidas entre a própria equipe, com usuários e com a comunidade.

Deve haver intervenção na rede social com a colaboração de profissionais de diferentes instituições e em referência às diversas pessoas significativas na vida do usuário, reconhecendo sua cidadania, independentemente da classificação de sua doença.

Além disso, a equipe deverá conhecer a área de abrangência do seu trabalho, identificando a forma de organização comunitária, os padrões culturais e sociais e suas formas potenciais de expressão. Deverá relacionar-se, de forma articulada, com as demais políticas públicas, incluindo programas de moradia, educação, geração de emprego e renda, expressão e arte, dialogando com as redes sociais, como conselhos de saúde, conselhos de direitos humanos, associações de bairros, grupos de auto-ajuda e outros setores representativos da sociedade. Para responder a todos esses desafios, será necessário o desenvolvimento de um processo de capacitação contínua e um permanente trabalho de investigação e avaliação.

\section{Descrição do Plantão de Emergência em Saúde Mental (PESM)}

Todas essas premissas norteavam as ações promovidas pelo Plantão de Emergência em Saúde Mental, em 1999, criado para organizar o atendimento das emergências ocorridas em Porto Alegre, RS, em substituição e transformação ao antigo modelo de atendimento prestado pela Central de Psiquiatria, desativada na mesma época, cujo prédio municipalizado estava sob interdição da Justiça.

No início, o PESM funcionava somente durante o dia e contava com 2 leitos de observação. Após 9 meses, passou a atender durante 24 horas, inclusive nos finais de semana, dispondo, para isso, de 7 leitos - 2 leitos para o Serviço de Observação (SO) e 5 leitos para Internação de Curta Duração (ICD).

Quanto ao perfil de sua clientela, um pequeno levantamento de dados realizado 
no primeiro ano já demonstrava os seguintes resultados: $60 \%$ da procura era por uso de substâncias psicoativas (álcool e outras substâncias), enquanto os $40 \%$ restantes incluíam sofrimento psíquico grave (psicoses, depressão) com exposição a risco social (risco de suicídio, abandono familiar, situação de rua e outros). De qualquer forma, ainda havia a necessidade de ampliação e de validação dessa amostra para que, a partir da comprovada fidedignidade dos dados, se pudesse melhorar e qualificar o atendimento em saúde mental na cidade em todos os níveis de complexidade da rede.

O espaço físico do PESM estava integrado a um centro de saúde, o que permitia também oferecer um atendimento clínico aos usuários que apresentavam sofrimento psicológico. Esse espaço estava composto da seguinte forma: 1 guichê de informação, 1 sala de acolhimento, 1 sala para serviço administrativo, 1 sala da coordenação, 4 consultórios que também eram utilizados, quando necessário, para fazer acolhimento, 1 sala para serviço de observação, 1 posto de enfermagem, 1 sala para internação de curta duração, 1 sala para atividades e refeições de usuários, 1 sala de descanso feminino para funcionárias, 1 sala de descanso masculino para funcionários, 1 copa-cozinha, 3 banheiros para funcionários, 4 banheiros para usuários, sendo 2 para banho com chuveiros. Contava, ainda, com uma equipe de trabalho formada pelos seguintes profissionais: 4 psicólogos, 5 enfermeiros, 4 assistentes sociais, 15 psiquiatras, 19 auxiliares de enfermagem e 3 técnicos de enfermagem.
Naquele momento, o acolhimento era assumido pelos assistentes sociais, psicólogos e enfermeiros, e raramente pelos médicos, pois havia ainda uma concepção, por parte dos mesmos, de que acolhimento e atendimento eram procedimentos separados, e não partes do mesmo processo. Dentro de tal concepção, o acolhimento dizia respeito, por exemplo, à recepção e à escuta do usuário sem exigência de pré-condição. Já o atendimento prestado pelos médicos estava condicionado à constatação da gravidade da situação.

O contato com outros serviços e recursos para encaminhamento dos usuários incluía contatos telefônicos, verbais e escritos aos demais serviços de saúde, aos familiares, ao trabalho, ao Judiciário e outros, procurando situar o usuário dentro de suas redes de relações, implicando-as no processo de cuidado. Esses contatos eram realizados pelos assistentes sociais, enfermeiros, psicólogos, auxiliares e técnicos de enfermagem.

As atividades externas, sempre que necessário, incluíam visita à família, acompanhamento de usuários em abrigo ou albergue ou em internação hospitalar, acompanhamento nas remoções em situação de risco em casa ou na via pública. Dentro das atividades externas, estava incluída também a presença de um integrante da equipe nas instâncias de controle social, como conselhos de saúde, de assistência social, tutelares e do orçamento participativo, bem como em conferências e seminários, visando a incluir o tema da saúde nos espaços de participação 
e decisão popular. Da mesma forma, os assistentes sociais, psicólogos, enfermeiros, técnicos e auxiliares de enfermagem eram os profissionais que se dispunham a realizar essas atividades.

A proposta de atendimento interdisciplinar, incluindo o parecer do conjunto dos profissionais sobre os encaminhamentos dos usuários, também se encontrava em fase de discussão e de aprofundamento, havendo, ainda, muitas dissensões por parte de alguns médicos e apoio e compreensão por parte de outros; era um período de contextualização dos saberes, redistribuição dos poderes e construção da proposta.

A equipe do PESM também promovia capacitação para profissionais que socorriam pessoas em situação de risco em saúde mental em via pública, como: policiais militares, socorristas do Serviço de Atendimento Móvel de Urgência do Pronto Socorro Municipal, Serviço de Abordagem Social de Rua e comunidades interessadas. A idéia era formar multiplicadores em prevenção em saúde mental que pudessem desconstruir a noção de periculosidade social que envolve os portadores de sofrimento mental em situação de crise e estreitar as parcerias entre esses setores.

O PESM trabalhava no sistema de Referência e Contra-Referência com os demais serviços de saúde mental da cidade, visando a potencializar a capacidade de atendimento e estabelecer um fluxo com a Rede de Atenção em Saúde Mental, que estava regionalizada em 11 distritos sanitários (DS) e apresentava a configuração apresentada na tabela 1.

Tabela 1- Distritos sanitários (DS) e serviços de saúde mental

\section{DS 1 Unidade Sanitária com Equipe de Saúde Mental}

DS 3 Centro de Saúde com Equipe de Saúde Mental

DS 4 Centro de Atenção Integral à Saúde Mental (CAIS Mental), Equipe de Saúde Mental e o Plantão de Emergência em Saúde Mental (PESM)

DS 5 Centro de Saúde com Equipe de Saúde Mental

DS 6 Equipe de Saúde Mental

DS 7 Centro de Saúde com Equipe de Saúde Mental

DS 8 Centro de Atenção Integral em Saúde Mental (CAIS Mental), Serviço Residencial Terapêutico (Moradia Protegida), Serviço de Geração de Renda, Equipe de Saúde Mental para Crianças e Adolescentes, Equipe de Saúde Mental para adultos, Equipe de Saúde Mental para Jovens e Adolescentes, casa para atender crianças e adolescentes usuários de SPA

DS 9 Unidade Sanitária com Equipe de Saúde Mental

DS 10 Unidade Sanitária com Equipe de Saúde Mental

Além do fluxo estabelecido com os serviços de saúde mental referidos, promoviam-se contatos com outros setores, como o de assistência social, para encaminhamento de usuários em situação de vulnerabilidade social ou em situação de rua, comunidades e fazendas terapêuticas e grupos de auto-ajuda para atendimento de dependentes químicos. Procurava-se também 
uma articulação com ONGs que trabalhavam com crianças e adolescentes e com as clínicas geriátricas para encaminhamentos de idosos, buscando sempre, em primeiro lugar, a integração das famílias e das comunidades no processo de cuidado.

Estava em curso também a organização de um fluxo específico para as emergências na rede de saúde mental, visando a melhorar o acesso aos serviços 24 horas em parceria com o Hospital Psiquiátrico São Pedro, que era referência no Estado para atender as emergências oriundas de toda a região metropolitana e do interior, ficando o PESM responsável por acolher apenas as emergências da rede municipal, conforme fluxograma na Figura 1.
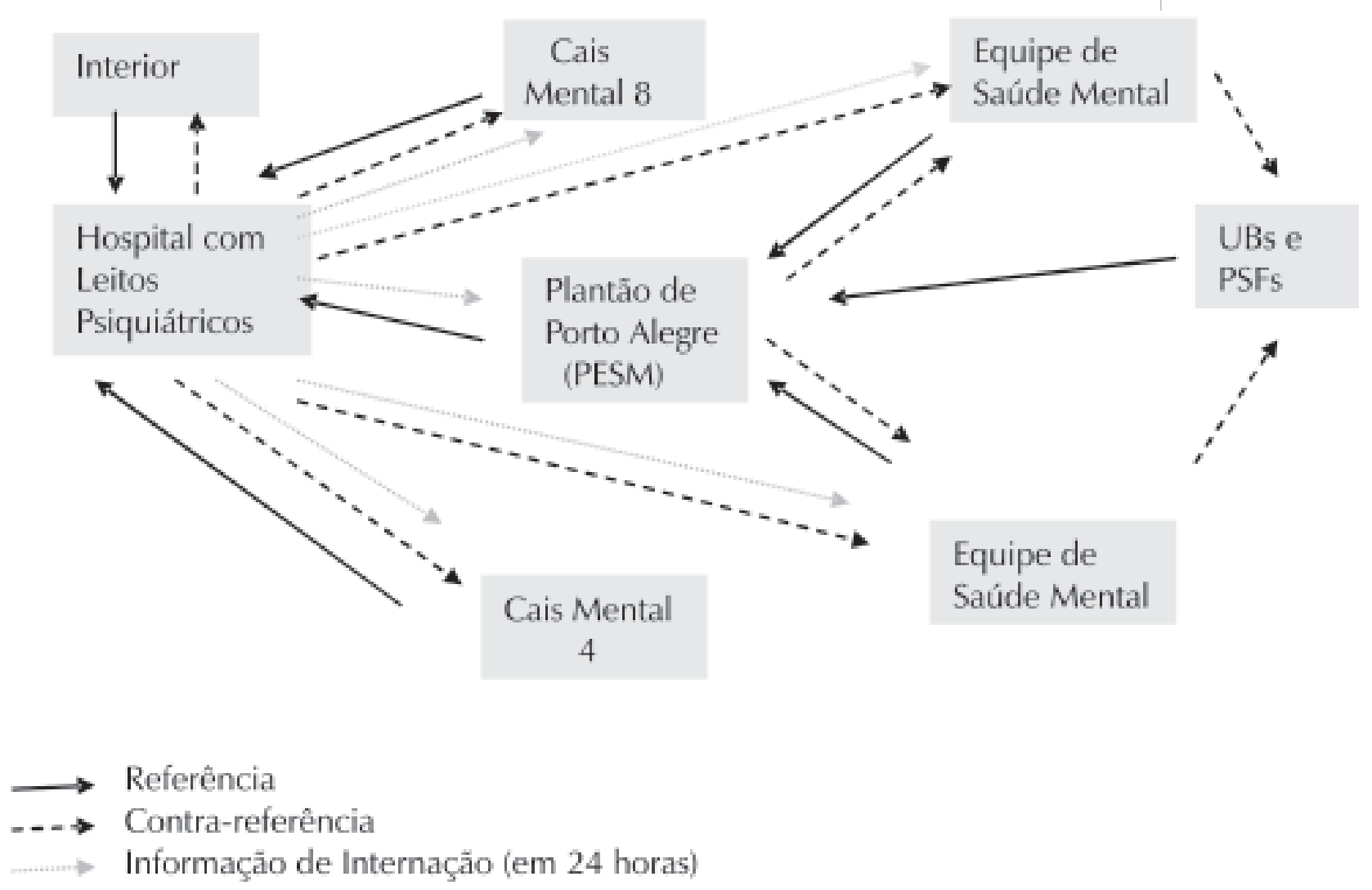

Figura 1 - Fluxograma para emergências psíquicas em Porto Alegre e interior do RS

\section{Considerações finais}

A partir dessa experiência, é importante ressaltar que o princípio de acolhimento e suas implicações práticas é que fazem a diferença na construção do fazer cotidiano em um Plantão de Emergência em Saúde
Mental (PESM). Embora, em alguns momentos, venham suscitar mais dúvidas do que conferir certezas, as inquietações geradas tanto no campo teórico quanto no prático impulsionam a equipe na direção 
de um balizamento humanizado e resolutivo das ações.

Ainda que o trabalho tenha ocorrido num contexto sinalizado pela multiplicidade de enfoques, disciplinas diversas e entendimentos muitas vezes divergentes, foi possível realizar ações de assistência e de cuidado e aprofundar conceitos como emergência e acolhimento em saúde mental no sentido de encontrar, em meio a tanta diversidade, o aprimoramento dessa prática. Mesmo reconhecendo-se a existência dos limites impostos pela falta de um fluxo mais eficiente de acolhida nos demais serviços de saúde em todos os níveis de complexidade e não apenas na emergência, acredita-se que, no cotidiano dessa clínica ampliada em construção, será possível promover desdobramentos muito significativos, capazes de produzir novas tecnologias direcionadas para a melhoria da atenção à gama de situações de sofrimento mental presentes na vida das pessoas.

Alerta-se, entretanto, para o cuidado a fim de não se cair na armadilha tão sedutora da solução imediata e correr o risco de se ter um serviço que deve oferecer acolhida e intervenção resolutiva em saúde mental para os casos de maior complexidade, promovendo a inclusão social e não transformando-se em um corredor de distribuição de laudos psiquiátricos ou numa sala de espera para as internações hospitalares. Por isso, a avaliação contínua sobre a prática cotidiana é extremamente necessária e deve incluir todos os envolvidos: a equipe de trabalho, os usuários do serviço e as demais instâncias de controle social. Outro aspecto especialmente destacado no decorrer deste trabalho foi a presença de alguns indicadores de inclusão e também de indicadores de barreiras para o acesso à saúde e à inserção social.

Entre os indicadores de inclusão, ressaltase que:

- a consolidação desse tipo de serviço como referência para as emergências psíquicas na rede do SUS modifica uma relação de atendimento que antes só era possível encontrar nas portas dos hospitais psiquiátricos, o que aumentava as internações;

a disposição de mais esse serviço para atender a rede de saúde e assistência de toda a cidade vem possibilitar o conhecimento das reais necessidades de saúde mental e favorecer o reordenamento das ações para melhoria da atenção;

o fato de este trabalho estar inserido em um serviço de emergência clínica geral, fora do hospital, possibilita o atendimento a emergências psicológicas e também a intercorrências orgânicas, sem excluir uma da outra, oferecendo um atendimento integral aos usuários de caráter ambulatorial, o que evita o estigma e o preconceito sobre a doença mental;

- com a abordagem interdisciplinar oferecida, é possível permitir que aqueles usuários que se encontram na fronteira da saúde e da assistência, em situação de risco e de vulnerabilidade social, acolhimento e encaminhamento adequados aos recursos assistenciais, o que permite uma atenção integralizada e evita a internação hospitalar injustificada, liberando o acesso à internação somente para aqueles casos que 
comprovadamente necessitem de hospitalização.

Entre as barreiras a serem transpostas, destaca-se que:

- a forma de encaminhamento ocorrida, naquele momento, no sistema, necessitava ser repensada no que tangia à falta de acolhida aos usuários em todos os serviços de saúde. Muitos deles passavam por uma espécie de peregrinação em busca de atendimento, sem obterem resposta, o que contribuía para o agravamento de suas crises e o aumento das emergências e das internações hospitalares;

o fato de o serviço de emergência permanecer de portas abertas durante 24 horas e universalizar o acesso transformavase na primeira escolha dos usuários antes da busca por outros serviços de saúde, o que resultava em superlotação da emergência, comprometendo a qualidade do acolhimento, invertendo a lógica da atenção primária e transformando o plantão numa porta de entrada para todas as demandas em saúde, sejam estas urgentes ou não;

a falta de uma política de atenção para além da saúde, que garanta a intersetorialidade nas ações através da criação de um protocolo conjunto que comprometa os diferentes setores das políticas públicas com o atendimento em saúde mental, traz sérias dificuldades, principalmente aos usuários com grave risco, que necessitam ser transportados até um serviço de emergência. Nesses casos, constatava-se uma dissociação entre a saúde e a segurança, a quem competia realizar o transporte, criando um impasse que quase sempre acabava sendo resolvido pelo critério da boa vontade de quem estava de plantão; tal prática só faz reforçar a visão estigmatizante que coloca o sujeito em sofrimento mental como um "caso de polícia", pois, na maioria dos casos, ainda cabe à polícia transportar esses usuários em crise, o que vem reforçar a representação no imaginário social de que essas pessoas são sempre "perigosas" e "incapazes";

- as situações de sofrimento mental, agravadas pelas condições materiais de vida da população, marcadas por exclusão e perdas de toda ordem (de emprego, de poder aquisitivo e, sobretudo, de direitos) bem como o aumento da violência são fatores mais graves que acabavam transcendendo os limites e obrigando a saúde, através de seus serviços, a responder também pelas condições materiais de vida, além de prestar assistência ao sofrimento físico e mental. Nesse aspecto, uma pesquisa da OMS (2001) confirmou esse fato, apontando como as principais causas do agravamento do sofrimento mental e suas conseqüências a falta de acesso a medicamentos, o preconceito e a pobreza. Para concluir, salienta-se que cabe à saúde acolher os indivíduos em sofrimento mental, mas não basta apenas à saúde incorporar a prática do acolhimento. É preciso que outros setores, como educação, assistência, trabalho e demais segmentos sociais também venham a assumir esse compromisso ético. A oferta de acolhida é o primeiro e decisivo passo rumo à transposição das barreiras que impedem a promoção da saúde e da cidadania, é o movimento fundamental para o fortalecimento do trinômio acolhimento- 
cuidado-inclusão. A reforma psiquiátrica em curso no País depende desses esforços para prosseguir.

Pode-se observar que grandes avanços já ocorreram no Estado do Rio Grande do Sul no que concerne às ações e serviços de saúde mental, muitos dos quais se devem, especialmente, ao trabalho dos profissionais engajados, de todas as categorias, que, aliados às instâncias da sociedade civil organizada, juntamente aos familiares e usuários do SUS e a o Poder Público comprometido com a superação dos manicômios, protagonizam essa história. A criação desse Plantão de Emergência em Saúde Mental (PESM) de Porto Alegre é um dos exemplos concretos desse esforço e a reafirmação do comprometimento desses setores com a gestão pública de saúde.

\section{Informações atuais sobre o Plantão de Emergência em Saúde Mental}

Como vemos, os desafios são imensos e há muito ainda por avançar. Há um longo trajeto a ser percorrido até que se alcancem os objetivos almejados por todos aqueles que lutam em busca de justiça social, de uma saúde humanizada, com melhor qualidade e fora dos muros de segregação.

No entanto, nesse sentido, é importante registrar que informações recentemente divulgadas sobre a atual situação da saúde mental pela Secretaria Municipal de Saúde de Porto Alegre, no ano de 2004, apontam alguns esforços já ocorridos nesse sentido e que avançam na direção da superação dessas dificuldades antes mencionadas. Dentre elas, destaca-se que:

- a inclusão da saúde mental na Central de Regulação das Internações Hospitalares vem permitir maior controle das internações;

- a remoção dos usuários em situação de grave risco para o Plantão de Saúde Mental já pode ser viabilizada pela integração de um trabalho realizado com o Serviço de Atendimento Móvel de Urgência do Pronto Socorro Municipal;

a recente criação do Programa Acolhimento, implantado em toda a rede de saúde da cidade com o objetivo de eliminar a existência das filas de espera, terá impacto positivo na demanda por serviços de emergência, diminuindo a procura;

- por outro lado, outro aspecto a ser ressaltado, não cabendo aqui um estudo mais aprofundado, diz respeito à mudança do perfil socioeconômico da população que buscava o serviço de emergência. Atualmente, grande parte dos usuários são oriundos da classe média, de modo diferente do início de funcionamento do serviço, quando a maioria da clientela provinha de classes menos favorecidas, incluindo moradores de rua. Esse fenômeno pode ser um indicador de maior confiabilidade nos serviços prestados pela rede pública de saúde, mas pode sugerir também um empobrecimento por parte da população, que, com baixo poder aquisitivo, não consegue mais manter seus planos de saúde privados. 
Psicóloga, especialista em Saúde e Trabalho - UFRGS. Coordenadora do Plantão de Emergência em Saúde Mental (PESM), SMS - Porto Alegre, RS, 1999 a 2001. Coordenadora da Pensão Pública Protegida Nova Vida (PPPNV), SMS Porto Alegre, RS,1998. Assessora Técnica de Planejamento e Programação em Saúde Mental, SMS - Porto Alegre, RS, 1999. Diretora de Políticas Sindicais do Sindicato dos

Psicólogos no Estado do Rio Grande do Sul (SIPERGS), 2000 a 2003. Coordenadora do Fórum Gaúcho de Saúde Mental (FCSM), 2003. Atual coordenadora do Programa de Assistência a DST/HIVIAIDS, da Divisão de Saúde do Departamento de Tratamento Penal, da Superintendência dos Serviços Penitenciários Secretaria de Justiça e Segurança do Estado do Rio Grande do Sul.

Av. Senador Salgado Filho, 204/62, CEP: 90010-220 Centro - Porto Alegre / RS. E-mail: ivarletegf@terra.com.br Tel.: (51) 32218514

AMARANTE, Paulo D.C. O Homem e a Serpente: outras Histórias para a Loucura e a Psiquiatria. Rio de Janeiro: Fiocruz, 1996.

CONFERÊNCIA NACIONAL DE SAÚDE MENTAL. 1. Brasília: 1987. Relatório Final, Ministério da Saúde, 1988.

CONFERÊNCIA NACIONAL DE SAÚDE MENTAL. 2. Brasília, 1992. Relatório Final, Ministério da Saúde, 1994.

CONFERÊNCIA NACIONAL DE SAÚDE. 8. Brasília, 1986. Relatório Final, Ministério da Saúde, 1986.

CONSELHO MUNICIPAL DE SAÚDE. Relatório da Comissão de Saúde Mental. Porto Alegre: 1993 (mimeo).

Constituição da República Federativa do Brasil - Brasília: Senado Federal, Centro Gráfico, 1988.

DELGADO, Jaques, M.F. (org). A Loucura na Sala de Jantar. São Paulo: Resenha, 1991.

DIÁRIO OFICIAL DE PORTO ALEGRE, 11 de janeiro de 1995.

FLEK, M.P. de Almeida. Emergências Psiquiátricas. In Busnello, Ellis, D'Arrigo, et, all. Rotinas em Psiquiatria. Porto Alegre: Artes Médicas, 1996.

FOUCAULT, M. História da Loucura. São Paulo: Perspectiva, 1993.

GUIA DE SERVIÇOS DE SAÚDE MENTAL, Secretaria Estadual da Saúde do Rio Grande do Sul: 2002.

KAPLAN, Harold I. SADOCK, Benjamin J. Compêndio de Psiquiatria. Porto Alegre: Artes Médicas, 1990.

KINOSHITA, Roberto Tykanori. Contratualidade e Reabilitação Psicossocial. In Pitta, Ana, M, F. (org.) Reabilitação Psicossocial no Brasil. São Paulo: Hucitec, 1996.

LAPLANCHE, Jean; PONTALIS. Vocabulário da Psicanálise. São Paulo: Martins Fontes,1992.
LEI ORGÂNICA DA SAÚDE (LOS) Lei no 8.080, de 19 de setembro de 1990 .

LOMBROSO, Cesar. O Homem Delinqüente. Porto Alegre: Lenz, 2001.

LONG, Maria Elisa, P. A. Diagnóstico Transestrutural da Crise. In Seminário; Urgência sem Manicômio. Núcleo Próformação e Pesquisa do Cersam/ Barreiro. Belo Horizonte: 1994.

MINISTÉRO DA SAÚDE; SECRETARIA DE POLÍTICAS DE SAÚDE; ÁREA TÉCNICA DE SAÚDE MENTAL. Por uma Política de Saúde Mental. Brasília: 1999.

MINISTÉRIO DA SAÚDE. Orientação para Funcionamento e Supervisão dos Serviços de Saúde Mental. Brasília: 1990.

ORGANIZAÇÃO MUNDIAL DA SAÚDE; ORGANIZAÇÃO PAN-AMERICANA DE SAÚDE. Declaração de Caracas, 1417 de novembro de 1990 .

ORGANIZAÇÃO PANAMERICANA DA SAÚDE; ORGANIZAÇÃ̃O MUNDIAL DA SAÚDE. Relatório sobre a Saúde Mental no Mundo: Saúde Mental: Nova Concepção, Nova Esperança. 2001.

PITTA, Ana M, F. Cuidando de Psicóticos. In Pitta, Ana M, F. (org.) Reabilitação Psicossocial no Brasil. São Paulo: Hucitec,1996.

PICHÓN-RIVIÉRE, Henrique. Teoria do Vínculo. São Paulo: Martins Fontes, 1991.

RIO GRANDE DO SUL. Lei da Reforma Psiquiátrica. Lei no 9.716, de 07 de agosto de 1992.

SAMPAIO, J.J. Saúde Mental. In Rouquayol, M. Zélia. Epidemiologia \& Saúde. 4 ed, Rio de Janeiro: MEDSI, 1999.

SARACENO, Benedetto, et. al. Manual de Saúde Mental. São Paulo: Hucitec, 1997.

TEIXEIRA, S.F.(org). Reforma Sanitária: em Busca de uma

Teoria. São Paulo: Cortez /Abrasco, 1989. 